\title{
Serum interleukin-17 levels are associated with nephritis in childhood-onset systemic lupus erythematosus
}

\author{
Karina de Oliveira Peliçari,' Mariana Postal,' Nailú Angelica Sinicato,' Fernando Augusto Peres,' \\ Paula Teixeira Fernandes," Roberto Marini,' ${ }^{\prime V}$ Lilian Tereza Lavras Costallat, "'I Simone Appenzeller ${ }^{1, \text { III,* }}$ \\ 'Universidade Estadual de Campinas (UNICAMP), Faculty of Medical Sciences, Rheumatology Laboratory, Campinas/SP, Brazil. "Universidade Estadual de \\ Campinas (UNICAMP), Faculty of Physical Education, Department of Sport Sciences, Campinas/SP, Brazil. "'I Universidade Estadual de Campinas (UNICAMP), \\ Faculty of Medical Science Department of Medicine, Rheumatology Unit, Campinas/SP, Brazil. ${ }^{\text {IV }}$ Universidade Estadual de Campinas (UNICAMP), Faculty of \\ Medical Science, Department of Pediatrics, Pediatric Rheumatology Unit, Campinas/SP, Brazil.
}

OBJECTIVES: To determine the serum interleukin-17 (IL-17) levels in childhood-onset systemic lupus erythematosus patients and to evaluate the association between IL-17 and clinical manifestations, disease activity, laboratory findings and treatment.

METHODS: We included 67 consecutive childhood-onset systemic lupus erythematosus patients [61 women; median age 18 years (range 11-31)], 55 first-degree relatives [50 women; median age 40 years (range 29-52)] and 47 age- and sex-matched healthy controls [42 women; median age 19 years (range 6-30)]. The childhood-onset systemic lupus erythematosus patients were assessed for clinical and laboratory systemic lupus erythematosus manifestations, disease activity [Systemic Lupus Erythematosus Disease Activity Index (SLEDAI)], cumulative damage [Systemic Lupus International Collaborating Clinics/American College of Rheumatology (ACR) Damage Index] and current drug use. Serum IL-17 levels were measured by an enzyme-linked immunosorbent assay using commercial kits.

RESULTS: The median serum IL-17 level was 36.3 (range 17.36-105.92) pg/mL in childhood-onset systemic lupus erythematosus patients and $29.47(15.16-62.17) \mathrm{pg} / \mathrm{mL}$ in healthy controls $(p=0.009)$. We observed an association between serum IL-17 levels and active nephritis $(p=0.01)$ and migraines $(p=0.03)$. Serum IL-17 levels were not associated with disease activity $(p=0.32)$, cumulative damage $(p=0.34)$, or medication use $(p=0.63)$.

CONCLUSION: IL-17 is increased in childhood-onset systemic lupus erythematosus and may play a role in the pathogenesis of neuropsychiatric and renal manifestations. Longitudinal studies are necessary to determine the role of IL-17 in childhood-onset systemic lupus erythematosus.

KEYWORDS: Interleukin-17; Childhood-onset systemic lupus erythematosus.

Peliçari KO, Postal M, Sinicato NA, Peres FA, Fernandes PT, Marini R, et al. Serum interleukin-17 levels are associated with nephritis in childhoodonset systemic lupus erythematosus. Clinics. 2015;70(5):313-317

Received for publication on December 10, 2014; First review completed on January 27, 2015; Accepted for publication on January 27, 2015

E-mail: appenzellersimone@yahoo.com

*Corresponding author

\section{INTRODUCTION}

Interleukin-17 (IL-17) is a potent pro-inflammatory cytokine that is produced by activated T lymphocytes (1). Th17 cells are a subset of CD4 ${ }^{+} \mathrm{T}$ lymphocytes named after their hallmark cytokine IL-17 (2), which represents the prototype of a recently identified cytokine family comprising six members (IL-17A, IL-17B, IL-17C, IL-17D, IL-17E, IL-17F) and five receptors (IL-17RA, IL-17RB, IL-17RC, IL-17RD, IL-17RE). IL-17 production is stimulated by IL-23 (3).

Copyright (c) 2015 CLINICS - This is an Open Access article distributed under the terms of the Creative Commons Attribution Non-Commercial License (http:// creativecommons.org/licenses/by-nc/3.0/) which permits unrestricted non-commercial use, distribution, and reproduction in any medium, provided the original work is properly cited.

No potential conflict of interest was reported.

DOI: $10.6061 /$ clinics/2015(05)01
IL-17 promotes inflammation by inducing local chemokine and cytokine secretion (4) and is essential for the clearance of certain pathogens such as bacteria and fungi. Moreover, IL-17 has been linked to the instigation of immune-mediated organ damage in the context of several autoimmune diseases (3). The frequency of IL-17-producing T cells is increased in the peripheral blood of adult systemic lupus erythematosus (SLE) patients $(4,6)$, and IL-17 production is abnormal in SLE patients (4-11). IL-17 levels are increased in adult SLE sera and correlate with disease activity $(9,12-15)$.

SLE is a heterogenic autoimmune inflammatory disease characterized by a wide spectrum of clinical manifestations and abnormal production of high-titer autoantibodies directed towards nuclear autoantigens $(5,7,8)$. Although the pathogenesis of SLE is not completely clear, genetic, environmental and hormonal factors play key roles in susceptibility and heterogeneous clinical manifestations (5). Childhood-onset SLE (cSLE) has a clinically different phenotype than adult-onset SLE (9). For instance, cSLE patients have increased kidney and central 
nervous system (CNS) involvement (16). These differences in the frequencies of clinical manifestations could be due to differences in the proinflammatory cytokine milieu in cSLE (9).

Only one previous study has analyzed IL-17 levels in cSLE (9). In this study of 40 cSLE patients, increased serum IL-17 levels were observed compared with healthy controls (9). An association between increased IL-17 levels and active disease, cutaneous manifestations and hematological manifestations has been described (9).

Therefore, the aim of our study was to determine the serum IL-17 levels in a large cSLE cohort, their first-degree relatives and healthy controls. Additionally, we evaluated the association of IL-17 with disease activity, laboratory findings and treatment features.

\section{METHODS}

\section{Subjects}

Sixty-seven consecutive cSLE patients followed at the Pediatric Rheumatology Unit of the State University of Campinas were invited to participate in this cross-sectional study. Patients were included in the present study if they (i) fulfilled at least four of the American College of Rheumatology (ACR) criteria (17), (ii) were younger than 16 years of age at disease onset, and (iii) had a follow-up duration of at least 6 months. Forty-seven first-degree relatives were included in this study. Fifty-five healthy controls without a history of any chronic disease (including a personal history of autoimmune diseases) were included as the control group.

The healthy controls were matched for age, sex and demographic background. This study was approved by the ethics committee at our institution, and written informed consent was obtained from each participant and/or legal guardian.

\section{Clinical, laboratory and treatment features}

The medical histories and clinical and serological features of each patient were reviewed in medical charts. The variables included in this database were the disease onset (defined as the age at which the first symptoms clearly attributable to SLE occurred), age at diagnosis (defined as the age at which the patients fulfilled four or more of the 1982 revised criteria for the classification of SLE (17)), and follow-up time (defined as the time from disease onset until July 2011).

All clinical manifestations and laboratory findings were recorded on the day of blood withdrawal. Active nephritis was diagnosed on the basis of the renal items of the SLE Disease Activity Index (SLEDAI) (18): proteinuria exceeding $0.5 \mathrm{~g} / 24$ hours and active urinary sediment [urinary casts, hematuria $(\geqslant 5$ red cells/high power field $[\mathrm{HPF}])$ and pyuria $(\geqslant 5$ leucocytes/HPF) in the absence of urinary tract infections].

Nephrotic syndrome was defined as proteinuria in excess of $3 \mathrm{~g} /$ day. Hematological abnormalities were ascribed to lupus only in the absence of bone-marrow suppression (leukopenia $<4000$ cells $/ \mathrm{mm}^{3}$, thrombocytopenia $<100,000$ cells $/ \mathrm{mm}^{3}$, and hemolytic anemia). We also assessed the presence of malar rash, discoid lesions, subacute cutaneous lesions, cutaneous vasculitis, photosensitivity, oral ulcers, arthritis, and serositis. Neurological and psychiatric involvement was defined according to the ACR guidelines (19).

The treatment prescribed at the time of blood withdrawal and any adverse events related to medication use were recorded. Doses of oral and parenteral corticosteroids were analyzed and converted to the equivalent doses of prednisone.

Antinuclear antibodies (ANA) were measured by indirect immunofluorescence using HEp-2 cells as the substrate and were regarded as positive if higher than 1:40. Double-stranded DNA (dsDNA) antibodies were determined by indirect immunofluorescence using Crithidia as the substrate and were considered positive if higher than 1:10. Precipitating antibodies to extractable nuclear antigens (ENA), including Ro (SSA), La (SSB), and Sm, were detected using a standardized enzyme-linked immunosorbent assay (ELISA) method and were considered positive if higher than 1:80. IgG- and IgM-isotype anticardiolipin antibodies (aCL) were measured using an ELISA (20). Lupus anticoagulant (LA) activity was detected by coagulation assays in platelet-free plasma obtained by double centrifugation, following the recommendation of the subcommittee on LA of the Scientific and Standardization Committee of the International Society of Thrombosis and Homeostasis (21). These measurements were performed twice at a 12-week interval.

\section{Diseases Activity/Cumulative Damage Evaluation}

Disease activity was measured by the SLEDAI 2000 (SLEDAI-2K) (18). The SLEDAI-2K comprises 24 weighted items grouped into 9 domains, representing organ systems. SLEDAI scores range between 0 and 105. Scores greater than 3 were considered active disease (22).

Cumulative SLE-related damage was identified in all patients using the Systemic Lupus International Collaborating Clinics (SLICC)/ACR Damage Index (SDI) at the time of blood withdrawal. SDI scores range from 0 to 47 . Damage was considered to be present if scores were $\geqslant 1(23)$.

\section{Mood and anxiety evaluation}

All subjects completed the Beck Depression Inventory (BDI) (24) and Beck Anxiety Inventory (BAI) (25) at study entry. For patients under sixteen years old, the Children's Depression Inventory (CDI) was applied. These scales comprise 21 items, each describing a common symptom of depression/anxiety. The respondent is asked to rate how much he or she has been bothered by each symptom over the past month on a 4-point scale, ranging from 0 to 3 . The items are summed to obtain a total score that can range from 0 to 63. The cutoffs used for the BDI are as follows: 0-13: no/minimal depression; 14-19: mild depression; 20-28: moderate depression; and 29-63: severe depression. For the BAI, the cutoffs are as follows: 0-7: no/minimal level of anxiety; 8-15: mild anxiety; 16-25: moderate anxiety; and 26-63: severe anxiety. The cutoff used for the CDI was 17.

\section{IL-17 assay}

Blood samples were collected from all participants, allowed to clot for $30 \mathrm{~min}$ at room temperature, and centrifuged at $3000 \mathrm{rpm}$ for $15 \mathrm{~min}$. Separated sera were kept in aliquots at $-80 \mathrm{C}$ until assayed. None of the samples were taken during an episode of acute or chronic infection (20). Serum IL-17 levels were measured by ELISA, using commercially available kits from R\&D Systems (London, UK), in accordance with the manufacturer's instructions. The detection range for IL-17 was $31.2-2000 \mathrm{pg} / \mathrm{ml}$, with a sensitivity of $15 \mathrm{pg} / \mathrm{ml}$ (human IL-17 kit).

\section{Statistical analysis}

All statistical analyses were performed using the Systat 12 software and SPSS Statistics 17.0 software, and the results are given as the median and range. The Kruskal-Wallis test was used to compare cytokine levels between groups. Spearman's correlation was used to correlate continuous variables (e.g., cytokine levels and SLEDAI, SDI, BDI and 
Table 1 - Demographic and clinical characteristics and IL-17 levels of the patients and controls included in the study.

\begin{tabular}{|c|c|c|c|}
\hline & Childhood-onset SLE patients $(\mathrm{N}=67)$ & First-degree relatives $(\mathrm{N}=55)$ & Healthy controls $(\mathrm{N}=47)$ \\
\hline \multicolumn{4}{|l|}{ Sex } \\
\hline Female & $61(91.04 \%)$ & $50(90.90 \%)$ & $42(89.36 \%)$ \\
\hline Age (years) & 18 (range $11-31$ ) & $40 *$ (range $29-52$ ) & 19 (range 6-30) \\
\hline Disease duration (years) & 5 (range $0-25$ ) & --- & --- \\
\hline SLEDAI & 4 (range $0-24$ ) & ---- & ---- \\
\hline Active disease $\mathrm{N}=35$ & 8 (range 4-24) & & \\
\hline Inactive disease $\mathrm{N}=32$ & 0 (range $0-2$ ) & & \\
\hline SDI & 0 (range $0-3$ ) & ---- & ---- \\
\hline Treatment & & ---- & ---- \\
\hline No medication & $6(8.9 \%)$ & & \\
\hline Prednisone & $61(91.1 \%)$ & & \\
\hline Dose (mg median/range) & $15(0-60)$ & & \\
\hline Hydroxychloroquine & $37(55.2 \%)$ & & \\
\hline Immunosuppressive drugs & $26(38.8 \%)$ & & \\
\hline Azathioprine & $16(23.8 \%)$ & & \\
\hline Cyclophosphamide & $3(4.4 \%)$ & & \\
\hline Cyclosporine & $5(7.7 \%)$ & & \\
\hline Methotrexate & $1(1.5 \%)$ & & \\
\hline Mycophenolate mofetil & $1(1.5 \%)$ & & \\
\hline \multicolumn{4}{|l|}{ Clinical finding } \\
\hline Nephritis & $24(35.8 \%)$ & & \\
\hline Rash malar & $6(8.9 \%)$ & & \\
\hline Alopecia & $3(4.5 \%)$ & & \\
\hline Vasculitis & $3(4.5 \%)$ & & \\
\hline Migraine & $3(4.5 \%)$ & & \\
\hline IL-17 (pg/ml) & $36.3 *(17.36-105.92)$ & $32.22(18.93-88.54)$ & $29.47 *(15.16-62.17)$ \\
\hline
\end{tabular}

$* p \leqslant 0.05$

BAI scores). Cytokine levels and categorical variables were compared using the Mann-Whitney $U$ test. The level of significance was set to $p<0.05$.

\section{RESULTS}

\section{Demographics}

We included 67 consecutive cSLE patients. Sixty-one (91.04\%) were female, with a median age of 18 years (range 11-31). The median disease duration was 5 years (range $0-26$ ). We included 55 first-degree relatives with a median age of 40 years (range 29-52) (Table 1). The control group comprised 47 healthy volunteers (42 women) with a median age of 19 (range 6-30). The patients and healthy controls were statistically comparable in terms of age and sex (Table 1).

\section{Clinical, laboratory and treatment features}

At the time of study entry, $35(52.2 \%)$ cSLE patients had active disease (SLEDAI >3), with a median SLEDAI score of 8 (range 4-24). Patients with inactive disease [N=32 (47.8\%)] had a median SLEDAI score of 0 [(range 0-2)]. Active nephritis $(35.8 \%)$, new malar rash $(8.9 \%)$, new alopecia $(4.5 \%)$, cutaneous vasculitis $(4.5 \%)$ and migraine $(4.5 \%)$ were the most frequently observed clinical manifestations (Table 2).

At the time of blood withdrawal, $6(8.9 \%)$ patients were not taking any medication. Fifty-nine (88\%) patients were receiving prednisone, 38 (57\%) were receiving hydroxychloroquine, and 26 (39\%) patients were receiving other immunosuppressive drugs.

With regard to mood and anxiety disorders, 41 (61\%) cSLE patients showed no anxiety symptoms, $16(24 \%)$ had mild symptoms, $6(9 \%)$ had moderate symptoms and $4(6 \%)$ had severe symptoms. For depression, 59 (88\%) cSLE patients showed no depression symptoms, $5(8 \%)$ had mild depression, $1(1 \%)$ had moderate depression, and $2(3 \%)$ had severe depression (Table 3).
Table 2 - Serum IL-17 levels compared with the main clinical manifestations.

\begin{tabular}{lccc}
\hline Clinical Manifestation & Median $(\mathrm{pg} / \mathrm{mL})$ & IQR & P-value \\
\hline Malar Rash & 37.11 & 10.28 & 0.5 \\
$\quad$ Yes (N=6) & 36.30 & 12.66 & \\
$\quad$ No (N=61) & & & 0.1 \\
Alopecia & 29.47 & 12.26 & \\
$\quad$ Yes (N=3) & 36.30 & 12.26 & \\
$\quad$ No (N=64) & & & 0.2 \\
Cutaneous manifestation & 33.16 & 12.93 & \\
$\quad$ Yes (N=8) & 36.30 & 12.78 & \\
$\quad$ No (N=59) & & & $0.01 *$ \\
Nephritis & 36.86 & 16.41 & \\
$\quad$ Yes (N=24) & 21.31 & 11.60 & \\
$\quad$ No (N=43) & & & 0.9 \\
Vasculitis & 39.49 & 12.55 & \\
$\quad$ Yes $(\mathrm{N}=4)$ & 35.27 & 12.55 & \\
$\quad$ No (N=63) & & & \\
\hline$* p \leqslant 0.05$ & & &
\end{tabular}

\section{IL-17 assay}

The median serum IL-17 levels were 36.3 (range $17.36-105.92) \mathrm{pg} / \mathrm{mL}$ in the cSLE patients and 29.47 (15.16-62.17) $\mathrm{pg} / \mathrm{mL}$ in the healthy controls $(p=0.009)$. No differences were found between the serum levels of the patients and first-degree relatives (median $32.22 \mathrm{pg} / \mathrm{mL}$, range: $18.93-88.54 \mathrm{pg} / \mathrm{mL} ; p=0.41$ ) or between the healthy controls and first-degree relatives $(p=0.11)$ (Figure 1).

Serum IL-17 levels were significantly increased in cSLE patients with migraines $(p=0.03)$ and with active nephritis $(p=0.01)$. However, serum IL-17 levels were not associated with disease activity $(p=0.32)$, cumulative damage $(p=0.34)$, anxiety $(p=0.42)$ or depression $(p=0.42)$. Serum IL-17 levels did not differ between patients with and without immunosuppressant use $(p=0.63)$. Upon analyzing each individual medication, no associations were observed. 
Table 3 - Serum IL-17 levels compared with the main neuropsychiatric manifestations.

\begin{tabular}{lcrc}
\hline Neuropsychiatric Manifestation & Median $(\mathbf{p g} / \mathrm{mL})$ & IQR & P-value \\
\hline BAI & & & 0.4 \\
Yes (N=26) & 36.86 & 10.90 & \\
$\quad$ No (N=41) & 38.05 & 11.67 & \\
BDI & & & 0.4 \\
$\quad$ Yes (N=8) & 36.58 & 9.29 & \\
$\quad$ No (N=59) & 36.88 & 11.85 & \\
Migraine & & & $0.03^{*}$ \\
$\quad$ Yes (N=3) & 36.58 & 13.55 & \\
$\quad$ No (N=64) & 28.33 & 12.12 & \\
\hline
\end{tabular}

$* p \leqslant 0.05$

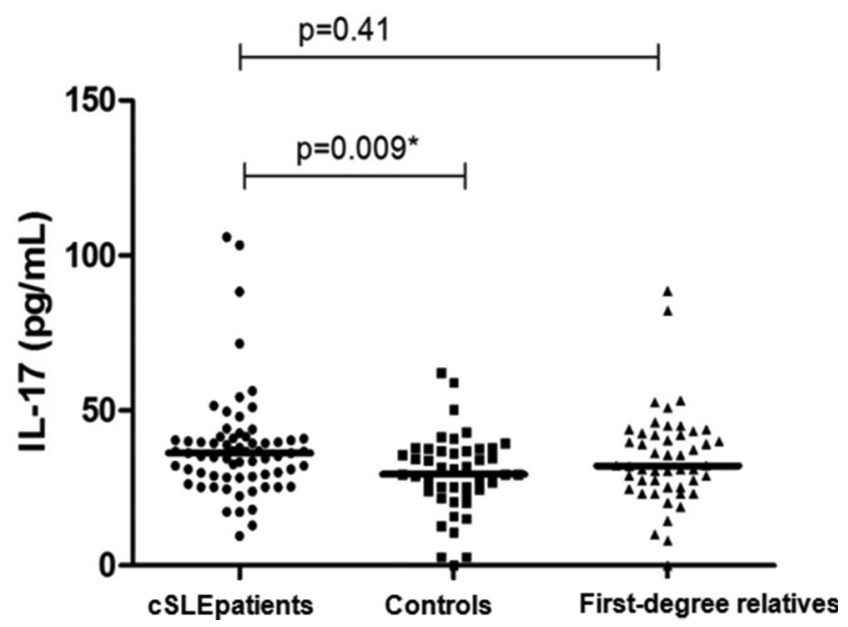

Figure 1 - Serum IL-17 levels observed in the three groups included in this study.

\section{DISCUSSION}

Recently, Th17 cells have been identified as a new $\mathrm{T}$ cell subset; the signature cytokines secreted by Th17 cells include IL-17A, IL-17F, IL-21, and IL-22 $(2,10,11)$. This array of cytokines can stimulate B lymphocytes and set off local inflammation and tissue injury, leading to SLE pathogenesis. Evidence supporting the role of IL-17 in SLE pathogenesis has been found in human lupus as well as in an animal model $(2,26)$.

IL-17 and other Th17 cytokines have been most commonly described as proinflammatory cytokines due to their expression in the lesions of patients with chronic inflammatory diseases and their role in inducing inflammation $(27,28)$. A significant fraction of the IL-17 produced in SLE patients derives from double-negative (DN) TCR- $\alpha \beta+\mathrm{CD} 4-\mathrm{CD} 8-\mathrm{T}$ cells (26). DN T cells represent a small T cell subset in healthy individuals. These cells are expanded in the peripheral blood of SLE patients and produce proinflammatory chemokines and cytokines, including IL-17, IFN- $\gamma$, and IL-1 $\beta$ (29). We observed an increase in serum IL-17 levels in cSLE patients compared with healthy controls. Our data also corroborate some studies in adult SLE patients $(6,10,12-15,27,28)$ and cSLE patients (9).

The association between IL-17 levels and disease activity remains controversial (9,10,12-15). Although some studies observed a positive association, we and other studies have found no association between IL-17 levels and disease activity $(27,28)$. These diverse findings may be explained by the heterogeneity of clinical and laboratory manifestations in SLE, the different sample size in the above-mentioned studies and variations in the principle and sensitivity of the ELISA tests.

We detected higher IL-17 levels in SLE patients with nephritis. Our data are in agreement with previous studies suggesting that IL-17 could contribute to the pathogenesis of kidney involvement in SLE patients $(13,28,30)$. Support for the pathogenic role of IL-17 derives from the fact that IL-17-producing T cells have been observed in the kidneys of patients with lupus nephritis (29). IL-17 is mostly produced by $\mathrm{CD} 4^{+}, \mathrm{CD} 8^{+}, \mathrm{CD} 4^{-} / \mathrm{CD} 8^{-}$, $\gamma / \delta \mathrm{T}$ cells, and Th17 cells. In human lupus nephritis, IL-17-expressing T cells migrate to the kidneys and contribute to inflammatory processes $(28,29,31)$. However, a recent study with cSLE patients did not demonstrate an association between IL-17 and nephritis (9). These findings may be due to the smaller number of patients included or to a different disease duration.

Studies in animal models have shown that $\mathrm{T}$ cells expressing IL-17 infiltrate the kidneys of SLE patients. A significant proportion of these cells are CD3 + CD4-CD8- DN T cells (26). Additionally, the authors showed that DN T cells from MRL/lpr mice express high levels of IL-17 and that as the disease progressively worsens, IL-17 and IL-23 receptor expression increases in lymphocytes (26).

In another study, IL-23R-deficient lupus-prone C57BL/ 6-lpr/lpr mice displayed decreased numbers of CD3+ CD42CD82 cells and IL-17A-producing cells in the lymph nodes and produced less anti-DNA antibodies. Additionally, clinical and pathological measures of lupus nephritis were abrogated. This experimental study clearly shows the importance of IL-23R-mediated signaling in the development of lupus nephritis and proposes the use of appropriate biologics to treat the disease (32).

A recent study demonstrated that Th17 cells react to CNS autoantigens and manifest a higher migratory capability to the CNS parenchyma compared WITH other T cell subpopulations due to their ability to penetrate the blood-brain barrier (11). CNS involvement is frequently observed in cSLE patients (33). In our study, we observed an association between increased IL-17 levels and migraines. To date, no studies in the literature have explored this association.

Previous studies have demonstrated an association between mood disorders and IL-17 levels $(34,35)$. The first study observed increased IL-17 levels in patients with rheumatoid arthritis and anxiety, and IL-17 levels were independently associated with higher anxiety scores (34). Another study observed increased IL-17 levels in patients with mood disorders compared with healthy controls (35). In our study, no association between IL-17 and mood disorders was observed. However, we evaluated mood disorders with a self-evaluation questionnaire of symptoms of depression/anxiety, which is not a diagnostic tool; this may have influenced the negative results.

A recent study with a cSLE cohort observed a correlation between IL-17 levels and disease activity and cutaneous and hematological manifestations (9). We did not observe any of these findings in our cohort. This can be explained by the different genetic background, different disease duration and different sample size (we had a larger number of patients).

Similarly to previous studies, we did not observe differences in IL-17 levels according to the use of immunosuppressants $(27,36)$.

SLE is an autoimmune disease, and although genetic susceptibility contributes to its inheritance, environmental factors are also important disease triggers (37). Previous studies have shown that healthy SLE family members have a significantly higher risk of developing SLE or other 
autoimmune diseases $(37,38)$. However, the IL-17 levels in first-degree relatives have never been studied. In our study, we observed that the IL-17 levels in first-degree relatives were elevated compared with controls, but this value was not significant.

In summary, IL-17 may play a role in the pathogenesis of neuropsychiatric and renal manifestations in cSLE patients. Longitudinal studies with regular serum analysis are necessary to determine the role of IL-17 in cSLE.

\section{ACKNOWLEDGMENTS}

Fundação de Amparo à Pesquisa do Estado de São Paulo/Brasil (FAPESP 2008/02917-0, 2010/13636-2 and 2012/21071-0), Conselho Nacional de Desenvolvimento Científico e Tecnológico/Brasil (CNPq 300447/2009-4, 471343/2011-0; 302205/2012-8; 473328/2013-5).

\section{AUTHOR CONTRIBUTIONS}

Peliçari KO, Marini R and Appenzeller S designed the study and were also responsible for data collection, data analysis and manuscript writing. Postal M, Sinicato NA and Peres FA were responsible for data collection, data analysis and manuscript writing. Costallat LTL was responsible for the study design, data analysis and manuscript writing.

\section{REFERENCES}

1. Nakae S, Nambu A, Sudo K, Iwakura Y. Suppression of immune induction of collagen-induced arthritis in IL-17-deficient mice. J Immunol. 2003;171(11):6173-7, http://dx.doi.org/10.4049/jimmunol.171.11.6173.

2. Yap DYH, Lai KN. Cytokines and their roles in pathogenesis of systemic lupus erythematosus: From basic to recent advances. J Biomed Biotechnol. 2010. 2010;365083, http://dx.doi.org/10.1155/2010/365083.

3. Nalbandian A, Crispín JC, Tsokos GC. Interleukin-17 and systemic lupus erythematosus: current concepts. Clin and Exp Immunology. 2009;157(2): 209-15, http://dx.doi.org/10.1111/cei.2009.157.issue-2.

4. Crispín JC, Tsokos GC. IL-17 in Systemic Lupus Erythematosus. J Biomed Biotechnol. 2010;22(5):499-503.

5. Su DL, Lu ZM, Shen MN, Li X, Sun LY. Roles of pro and antiinflammatory cytokines in the pathogenesis of SLE. J Biomed Biotechnol. 2012;2012:347141, http://dx.doi.org/10.1155/2012/347141.

6. Crispín JC, Tsokos GC. Interleukin-17-producing $\mathrm{T}$ cells in lupus. Curr Opin Rheumatol. 2010:22(5):499-503, http://dx.doi.org/10.1097/BOR. 0b013e32833c62b0.

7. Sung YK, Park BL, Shin HD, Kim LH, Kim SY, Bae SC. Interleukin-10 gene polymorphisms are associated with the SLICC/ACR Damage Index in systemic lupus erythematosus. Rheumatology (Oxford). 2006;45(4): 400-404.

8. Ma J, Yu J, Tao X, Cai L, Wang J, Zheng SG. The imbalance between regulatory and $\mathrm{IL}-17$ secreting $\mathrm{CD} 4+\mathrm{T}$ cells in lupus patients. Clin Rheumatol. 2010;29(11):1251-8, http://dx.doi.org/10.1007/s10067-0101510-7.

9. Rana A, Minzi RW, Aggarwali R, Anand S, Pasricha N, Singh S. Gene expression of cytokines (TNF-alpha, IFN-gamma), serum profiles of IL-17 and IL-23 in pediatric systemic lupus erythematosus. Lupus. 2012;21(10): 1105-12, http://dx.doi.org/10.1177/0961203312451200.

10. Chen XQ, Yu YC, Deng HH, Sun JZ, Dai Z, Wu YW, et al. Plasma IL-17A is increased in new-Onset SLE patients and associated whit disease activity. J Clin Immunol. 2010; 30(2):221-5, http://dx.doi.org/10.1007/s10875-0099365-x.

11. Okada, H, Khoury SJ. Type 17 T-Cell in Central Nervous System Autoimmunity and tumors. J Clin Immunol. 2012; 32(4):802-8, http:/ /dx.doi. org/10.1007/s10875-012-9686-z.

12. Wong CK, Lit LCW, Tam LS, Li EK, Wong PT, Lam CW. Hyperproduction of IL-23 and IL-17 in patients with systemic lupus erythematosus implications for Th17 mediated inflammation in auto-immunity. Clin Immunol. 2008; 127(3):385-93, http:/ /dx.doi.org/10.1016/j.clim.2008.01.019.

13. Dolff S, Quandt D, Wilde B, Feldkamp T, Hua F, Cai X, et al. Increased expression of costimulatory markers CD134 and CD80 on interleukin-17 producing T cells in patients with systemic lupus erythematosus. Arthritis Res. Ther. 2010; 12(4):R150, http://dx.doi.org/10.1186/ar3100.

14. Wong CK, Ho CY, Li EK, Lam CWK. Elevation of pro-inflammatory cytokine (IL-18, IL17, IL-12) and Th2 cytokine (IL-4) concentrations in patients with systemic lupus erythematosus. Lupus. 2009;9(8):589-93, http:/ /dx.doi.org/10.1191/096120300678828703.

15. Gigante A, Gasperini ML, Afeltra A, Barbano B, Margiotta D, Cianci R, et al. Cytokines expression in SLE nephritis. Eur Rev Med Pharmacol Sci. 2011;15(1):15-24.
16. Tucker LB, Menon S, Sohaller JG, Isenberg DA. Adult and childhoodonset systemic lupus erythematosus: a comparison of onset, clinical features, serology and outcome. Br J Rheumatol. 1995;34(9):866-72, http://dx.doi.org/10.1093/rheumatology/34.9.866.

17. Tan EM, Cohen AS, Fries JF, Masi AT, McShane DJ, Rothfield NF, et al. The 1982 revised criteria for the classification of systemic lupus erythematosus. Arthritis Rheum. 1982;25(11):1271-7, http://dx.doi.org/10.1002/ (ISSN)1529-0131.

18. Gladman DD, Ibañez D, Urowitz MB. Systemic lupus erythematosus disease activity index 2000. J Rheumatol. 2002; 29(2):288-91.

19. ACR Ad Hoc Committee on Neuropsychiatric Lupus Nomencalture. The American College of Rheumatology nomenclature and case definitions for neuropsychiatric lupus syndromes. Arthritis Rheum. 1999:42(4):599-608.

20. Harris EN, Gharavi AE, Patel SP, Hughes GR. Evaluation of the anticardiolipin antibody test: report of an international workshop held 4 April 1986. Clin Exp Immunol. 1987; 68(1):215-22.

21. Brandt JT, Triplett DA, Alving B, Scharrer I. Criteria for the diagnosis of lupus anticoagulants: an update. On behalf of the Subcommittee on Lupus Anticoagulant/Antiphospholipid Antibody of the Scientific and Standardisation Committee of the ISTH. Thromb Haemost. 1995;74(4): 1185-90.

22. Yee CS, Farewell VT, Isenberg DA, Griffiths B, Teh LS, Bruce IN, et al. The use of Systemic Lupus Erythematosus Disease Activity Index-2000 to define active disease and minimal clinically meaningful change based on data from a large cohort of systemic lupus erythematosus patients. Rheumatology (Oxford). 2011;50(5):982-8.

23. Gladman DD, Urowitz MB, Goldsmith CH, Fortin P, Ginzler E, Gordon C, et al. The reliability of the Systemic Lupus International Collaborating Clinics/American College of Rheumatology Damage Index in patients with systemic lupus erythematosus. Arthritis Rheum. 1997;40(5):809-13, http://dx.doi.org/10.1002/(ISSN)1529-0131.

24. Beck AT, Ward CH, Mendelson M, Mock J, Erbaugh J. An inventory for measuring depression. Arch Gen Psychiatry. 1961;4:561-71, http://dx. doi.org/10.1001/archpsyc.1961.01710120031004.

25. Beck AT, Epstein N, Brown G, Steer RA. An inventory for measuring clinical anxiety: Psychometric properties. J Consult Clin Psychol. 1988; 56(6):893-7, http:/ / dx.doi.org/10.1037/0022-006X.56.6.893.

26. Zhang Z, Kyttaris VC, Tsokos GC. The role of IL-23/IL-17 Axis in Lupus Nephritis. J Immunol. 2009;183(5):3160-9, http://dx.doi.org/ 10.4049/jimmunol.0900385

27. Zhao XF, Pan HF, Yuan EH, Zhang WH, Li XP, Wang GH, et al. Increased serum interleukin 17 in patients whit systemic lupus erythematosus. Mol Biol Rep. 2010;37(1):81-5, http:/ /dx.doi.org/10.1007/s11033-009-9533-3.

28. Mok MY, Wu HJ, Lo Y, Lau CS. The relation of interleukin 17 (IL-17) and IL-23 to Th1/Th2 cytokines and disease activity in systemic lupus erythematosus. J Rheumatol. 2010; 37(10):2046-52, http://dx.doi.org/ 10.3899/jrheum.100293.

29. Crispín JC, Oukka M, Bayliss G, Cohen RA, Van Beek CA, Stillman IE, et al. Expanded double negative $\mathrm{T}$ cells in patients with systemic lupus erythematosus produce IL-17 and infiltrate the kidneys. J Immunol. 2008;181(12):8761-6, http://dx.doi.org/10.4049/jimmunol.181.12.8761.

30. Dong C. Diversification of T-helper-cell lineages: finding the family root of IL-17 producing cells. Nat Rev. Immunol. 2006;6(4):329-33, http://dx.doi. org/10.1038/nri1807.

31. Miyake K, Akahoshi M, Nakashima H. Th Subset balance in Lupus Nephritis. J Biomed Biotechnol. 2011. 2011; 980286., http://dx.doi.org/ $10.1155 / 2011 / 980286$.

32. Kyttaris VC, Zhang Z, Kuchroo KV, Oukka M, Tsokos GC. Cutting Edge: IL:23 Receptor Deficiency prevents the development of Lupus Nephritis in C57BL/6-ipr/ipr Mice. J Immunol. 2010;184(9):4605-9, http://dx.doi. org/10.4049/jimmunol.0903595.

33. Postal M, Costallat LTL, Appenzeller S. Neuropsychiatric manifestations in systemic lupus erythematosus: epidemiology pathophysiology and management. CNS Drugs. 2011; 25(9):721-36, http://dx.doi.org/10.2165/ 11591670-000000000-00000.

34. Liu Y, Ho RC, Mak A. The role of interleukin (IL)-17 in anxiety and depression of patients with rheumatoid arthritis. Int J Rheum Dis. 2012; 15(2):183-7, http://dx.doi.org/10.1111/j.1756-185X.2011.01673.x.

35. Vieira MMM, Ferreira TB, Pacheco PA, Barros PO, Almeida CR, AraújoLima CF, et al. Enhanced Th17 phenotype in individuals with generalized anxiety disorder. J Neuroimmunol. 2010;229(1-2):212-8, http://dx.doi. org/10.1016/j.jneuroim.2010.07.018.

36. Cheng F, Guo Z, Xu H, Yan D, Li Q. Decreased plasma IL-22 levels, but not increased IL-17 and IL-23 levels, correlate with disease activity in patients with systemic lupus erythematosus. Ann Rheum Dis. 2009;68(4):604-6, http://dx.doi.org/10.1136/ard.2008.097089.

37. Niewold TB, Hua J, Lehman TJ, Harley JB, Crow MK. High serum IFN-alpha activity is a heritable risk factor for systemic lupus erythematosus. Genes Immunol. 2007;8(6):492-502, http://dx.doi.org/10.1038/sj.gene.6364408.

38. Niewold TB, Adler JE, Glenn SB, Lehman TJ, Harley JB, Crow MK Age-and sex-related patterns of serum interferon-alpha activity in lupus families. Arthritis Rheum. 2008; 58(7):2113-9, http:/ /dx.doi.org/10.1002/ art.v58:7. 